\title{
Access to Healthcare: Issues of Measure and Method
}

Krishna Regmi* and Gurch Randhawa

University of Bedfordshire, UK

Health services are much improved in terms of results: people now live longer and are treated faster, healthcare institutions have advanced and professionals specialise in treating patients' conditions, and in general healthcare practices are evidence-informed and are implemented through evidence-based practice. Access to health care has been an important dimension in public health policy in many healthcare settings. As Aday and Anderson [1] ${ }^{(p .4)}$ discuss, access to healthcare from equity perspectives should fulfil three assumptions: first, this is a fundamental right to healthcare; second, health resources [3Ms : minute (time), manpower, materials] are always limited; and third, health policy should be evidence-based in practice. One argument behind such assumptions is that the 'modern healthcare system may in fact be ineffectual or even deleterious in effecting health in patients who use it' $[2,3]$.

It still does matter how one assesses people's healthcare needs, and who plans for and delivers such needs. With whom (partnership and networking), and at what levels - central, regional or local - are equally important in terms of how people gain access to healthcare, and the impacts on their health and wellbeing [4]. Access generally relates to people's ability to use health services when and where they are needed [1]. It is also concerned with the normative goal of healthcare systems [5]. Several authors [6-10] argue that determinants of healthcare access are the types and quality of services, including the costs, time, distance (ease of travel) as well as regular interface between service users and healthcare providers.

Access to care needs to be considered in the context of an increasingly globalised world. This means recognising the diversity of the patients we serve coming from a range of cultural, ethnic and faith backgrounds. It is therefore important for commissioners, services providers and researchers to examine the concept of patient access to quality care - how patients gain access to services? and how services are perceived by patients and care providers? The premise being that services need to be relevant and effective if the population is to have access to quality care for improved health outcomes. The concept of access operates on multiple levels. Overarching processes intended to promote access in care include patient education, empowerment and cultural competency. Patient education aims to equip people with the knowledge, skills and confidence to integrate effective care into their daily lives. Empowerment is a core standard of many UK care pathways as described in National Institute for Health and Care Excellence (NICE) guidance and National Service Frameworks [11], ensuring that people are informed and engaged in their care underpins the delivery of patient centred care. As chronic disease management typically involves a considerable element of self-care, clinical guidelines for effective care suggests it should be aligned with needs and preferences of people with long-term conditions and be culturally appropriate.

Whilst it has been contested whether empowerment itself is relevant for all groups of patients and therefore culturally appropriate in itself, it is universally agreed that for self management to be supported there needs to be collaboration and communication between patient and healthcare provider from the outset and there on afterwards. The degree to which this results in mutual understanding, and a shared approach between patient and provider on the care process describes concordance. The extent to which there is understanding of the social and cultural influences on healthcare interactions and how care is delivered in a way to maximise effectiveness taking these into account describes cultural competency of services.
Given the policy impetus outlined above, it is imperative for healthcare providers to consider their role in facilitating access which could include the provision of meaningful information to support patients to make decisions about their own care. For inequalities in access to be reduced, cultural competency of services must increase and therefore should be a key objective for local service commissioning and delivery. Care pathways are complex interventions and as a means of improving quality and maximizing resources are necessarily context based. Local services therefore may find that broadening the understanding of concordance within a culturally competent framework and applying it to the local system as a whole is a useful approach to planning and achieving effective access to care. Understanding how this can lead to reduced inequalities in access requires an evaluation of the care pathway as a complex intervention so that the mechanisms which bring about improvements can be identified and supported.

The fundamental question, however, remains unanswered, i.e. how can we measure access to healthcare, and what methods should be utilised within the complexities of its meaning, as access to healthcare appears rather a political than an operational. While conceptualising its meaning, two aspects are often emerged in many literatures: first, people often try to equate it with the demographic profiles of the population (for example, income, race, residence); second, it relates to health systems (distribution of resources, available services including health and non-health human resources) [1].

There are complexities exhibited in measuring access to and utilisation of healthcare services. Anderson [12] offers five different approaches related to the utilisation of healthcare - socio-cultural, socio-demographic, social-psychological, organisational and social systems. But others view it within the configuration of IPO (inputs, processes, outputs/outcomes) indicators [13]. One fundamental philosophical assumption about health systems is that people should be at the centre of a nation's health plan, with policy-makers, planners and decision-makers revolving around the circuit of people's healthcare plans. Politicians are accountable and responsible for addressing people's healthcare needs in general and their overall welfare in specific. In Kronenfeld's [14] view, cost, quality and access to health are three important components in any health service delivery. We argue that overall availability of healthcare services is another form of measurement, whilst others' views are slightly different as they attempt to it as 'matching concepts' i.e. peoples needs vs available (supply) services, considering social-economic parameters of those groups to bring positive change in people's health [1].

Healthcare has now has been recognised as a multidisciplinary entity

*Corresponding author: Krishna Regmi, Department of Clinical Education and Leadership, Institute for Health Research, University of Bedfordshire, Luton LU2 8LE, UK; Tel: 44-(0)1582-743475; E-mail: krishna.regmi@beds.ac.uk

Received April 10, 2013; Accepted July 02, 2013; Published July 05, 2013

Citation: Regmi K, Randhawa G (2013) Access to Healthcare: Issues of Measure and Method. Primary Health Care 3: 136. doi:10.4172/2167-1079.1000136

Copyright: $\odot 2013$ Regmi K, et al. This is an open-access article distributed under the terms of the Creative Commons Attribution License, which permits unrestricted use, distribution, and reproduction in any medium, provided the original author and source are credited. 
Citation: Regmi K, Randhawa G (2013) Access to Healthcare: Issues of Measure and Method. Primary Health Care 3: 136. doi:10.4172/21671079.1000136

capturing both 'means and ends' to make lasting changes in people's health outcomes. Health outcomes might be intended (being free from diseases) and non-intended (economically productive mass for development). People have different views, therefore, when interpreting the meaning of 'access'. Medical socialists view it, for example, as soft indicators - quality with some degree of services quantity with customer's satisfaction; whilst health economists view it more as a cost attribute. Health policy relates access to the degree of power and authority left to the local authorities, whilst health geographers view it as through geographic variation in population and spatial organisations (numbers, sizes, types and locations) in the analysis of disease patterns and resource allocation $[4,15]$.

Similarly, Aday et al. [16] capture the remit of accessing healthcare through the dimensions that are potential and actual entry of a given population group to the healthcare delivery system' - the key philosophical assumption behind this approach is that in accessing healthcare, health services should be tailored to the needs of the people rather than distributing on the basis of demographic attributes. Recently, geographical access has been given much emphasis in health services. As McLafferty [4] suggests, we can measure access on two levels: area-based (ratio of population need to service available, e.g. physician to population ratio, where there is a problem in rural areas), or distance-based (distance or travel time or costs vs location of service units - centre, region and local and choices of units). As Wennberg [17] suggests, a distance-based approach would often relate to the aspect of service access and utilisation. Though access to healthcare is often viewed as the determinant of user 'satisfaction' and 'utilisation', health professionals' views are often ignored. In Aday and Anderson's [1] view, a healthcare professional's input is important to assess the delivery of health services (distribution of resources), and health needs, including users' attitudes in seeking healthcare.

We argue that examining the complexities and development of needbased measurements might be the best way of the population accessing healthcare needs. Sometimes other variables such as demographic attributes - age, sex, race, income, residence - would provide added value to compare the levels of needs as well as assess the degree of supply and demand. However, some challenges still exist to demonstrate some relationship between access and improved health outcomes, as there are many non-health factors which are equally responsible in people's overall health status. Donabedian's [18] (p.111) statement might be worthwhile to capture the wider remit of understanding and measuring access to health:

'The proof of access is use of service, not simply the presence of a facility. Access can, accordingly, be measured by the level of use in relation to 'need'. One should recognise, however, that clients and professionals evaluate 'needs' differently. Furthermore one must distinguish two components in use of service: 'initiation' and 'continuation'. This is because different factors influence each, though any one factor may influence both. It is hardly necessary to emphasise that barriers to access are not only financial but also psychological, informational, social and organisational, spatial, temporal, and so on.'

We argue that to measure the access to healthcare, there should be some provisions to assess and re-assess people's health needs regularly, and fit this in within the 'IPO configuration' to see to what extent the existing systems would address the people's healthcare needs.
At present, criteria for accessing healthcare are narrowly focused, therefore developing established and acceptable criteria revealing both qualitative and quantitative attributes, encompassing users' and practitioners' perspectives within the dimensions of 'utilisation' and 'satisfaction', would be paramount.

\section{References}

1. Aday LA, Anderson RM (1981) Equity of access to medical care: a conceptual and empirical overview. Medical Care 19: 4-27.

2. Carlson R (1975) The end of medicine. New York: John Wiley and Sons.

3. Illich I (1977) Medical Nemesis: the expropriation of health. Toronto: Bentam Books.

4. McLafferty SL (2003) GIS and healthcare. Annu Rev Public Health 24: 25-42.

5. Blumstein JF, Zubkoff M (1979) Public choice in health: problems, politics and perspectives on formulating national health policy. J Health Polit Policy Law 4 382-413.

6. Goodman DC, Fisher E, Stukel TA, Chang C (1997) The distance to community medical care and the likelihood of hospitalisation: is closer always better? Am J Public Health 87: 1144-1150.

7. Haynes R, Gale S, Mugford M, Davies P (2001) Cataract surgery in a community hospital outreach clinic: patient costs and satisfaction. Soc Sci Med 53:1631-1640.

8. Haynes R, Bentham G, Lovett A, Gale S (1999) Effects of distances to hospita and GP surgery on hospital inpatient episodes controlling for needs and provision. Soc Sci Med 49: 425-433.

9. Joseph AE, Phillips DR (1984) Accessibility and utilisation: geographica respectives on healthcare delivery.SAGE.

10. Fortney J, Rost K, Zhang M, Warren J (1999) The impact of geographic accessibility on the intensity and quality of depression treatment. Medical Care 37: 884-893.

11. Department of Health (2003) National service framework for diabetes. London: $\mathrm{DoH}$.

12. Anderson JG (1973) Health services utilisation: framework and review. Health Serv Res 8: 184-199.

13. Freeman H (1989) Handbook of medical sociology. Prentice-Hall.

14. Kronenfeld JJ (2007) Access, quality and satisfaction with care concerns of patients, providers and insurers. Bingley, UK: Emerald Publishing Group.

15. Rushton G, Elmes G, McMaster R (2000) Considerations for improving geographic information research in public health. URISA J 12: 31-49.

16. Lu Ann Aday, Ronald M Andersen, Gretchen Voorhis Fleming (1980) Healthcare in the US: equitable for whom? SAGE Publications.

17. Wennberg J (1998) The Dartmouth Atlas of health care. Chicago: Am Medica Hospital Publication.

18. Donabedian A (1972) Models for organising the delivery of personal health services and criteria for evaluating them. Milbank Mem Fund Quart 50: 103 154 